\title{
FAKTOR YANG MEMPENGARUHI KEJADIAN STUNTING PADA BALITA USIA 12-59 BULAN DI WILAYAH KERJA PUSKESMAS CAMPALAGIAN
}

\author{
Nurisriani Najamuddin ${ }^{1}$, Reni Rahmadani², Suriany ${ }^{3}$ \\ ${ }^{1,2,3}$ Program Studi S1 Keperawatan, STIKES Bina Generasi Polewali Mandar
}

\begin{abstract}
Background: Stunting problems in toddlers, which until now are still a special concern in the world because it can inhibit the physical and mental development of children. Stunting is a chronic malnutrition problem caused by a lack of nutrient intake over a long period of time due to food intake that is not in accordance with the nutritional needs of the body. Toddlers who experience stunting will cause increased risk and stunted growth and development of children. The method used in this study was observational analytic with a controud case design. Sampling using proportional random sampling technique, obtained 86 respondents in accordance with the inclusion criteria, data collection was done using questionnaire sheets and using KMS to observe birth weight in infants, height and weight of the last weighing at the time of the study with questionnaire filling. The collected data is then processed by using the Chi Square test with $\alpha<0.05$. The results of the statistical test showed that BBLR ( $p=0.005)$, Exclusive breastfeeding $(p=0.104), M p-A S I(p=0.121)$. The conclusion in this study is that BBLR affects the incidence of stunting, Exclusive breastfeeding and breastfeeding does not affect the incidence of stunting in children aged 12 to 59 months at the Campalagian Health Center in Polewali Mandar district.
\end{abstract}

\section{Keywords: Stunting, BBLR, Exclusive Breastfeeding and Breastfeeding Mp-ASI.}

\section{PENDAHULUAN}

Kesehatan merupakan hak asasi manusia dan salah satu unsur kesejahteraan yang harus diwujudkan sesuai dengan cita-cita bangsa Indonesia sebagaimana dimaksud dalam Pancasila dan Undang-undang Dasar 1945. Oleh karena itu, kesehatan yang optimal bagi seluruh warga masyarakat Indonesia merupakan hal yang harus dicapai. Kesehatan yang optimal dapat dicapai dengan meningkatkan pelayanan kesehatan masyarakat, salah satunya berupa pelayanan gizi masyarakat yang bertujuan untuk meningkatkan status gizi masyarakat (Angkat, 2018).

Non public health problem yang ditetapkan oleh WHO untuk masalah kependekan yaitu sebesar 20\%, maka Indonesia masih dalam kondisi bermasalah kesehatan

masyarakat. Dengan jumlah tersebut, Indonesia menduduki peringkat ke-5 terbanyak stunting di dunia (keadaan ini hanya lebih baik dari India, Tiongkok, Nigeria, dan pangan di tingkat rumah tangga Pakistan), (Kullu et al., 2018).

Kejadian balita pendek atau biasa disebut dengan stunting merupakan salah satu masalah gizi yang dialami oleh balita di dunia saat ini. Pada tahun 2017 22,2\% atau sekitar 150,8 juta balita di dunia mengalami stunting. Namun angka ini sudah mengalami penurunan jika dibandingkan dengan angka stunting pada tahun 2000 yaitu 32,6\%. Pada tahun 2017, lebih dari setengah balita stunting di dunia berasal dari Asia (55\%) sedangkan lebih dari sepertiganya (39\%) tinggal di Afrika. Dari 83,6 juta balita stunting di Asia, proporsi terbanyak berasal dari Asia Selatan (58,7\%) dan proporsi paling sedikit di Asia Tengah (0,9\%) (RI, 2018).

Stunting sudah dimulai sejak sebelum kelahiran disebabkan karena gizi ibu selama kehamilan buruk, pola makan yang buruk, kualitas makanan juga buruk dan intensitas frekuensi menderita penyakit yang sering. Stunting berkaitan erat dengan ASI Eksklusif dan pemberian makanan pendamping ASI. 
Kejadian balita stunting lebih rendah pada balita yang mendapatkan ASI Eksklusif. Pemberian makanan pendamping ASI merupakan faktor pencegah terjadinya gizi buruk (Angkat, 2018).

Berdasarkan data dari Dinas Kesehatan Polewali Mandar pada tahun 2018 wilayah kejadian stunting terbesar berada di wilayah kerja Puskesmas Campalagian sebesar 784 dari jumlah total 5966 kejadian stunting di seluruh wilayah Kabupaten Polewali Mandar yang terbagi dari 20 Wilayah kerja Puskesmas. Oleh karena itu peneliti gtertarik melakukan penelitian diwilayah kerja puskesmas Campalagian. Terdapat 13 Desa dengan kejadian stunting tertinggi di wilayah kerja puskesmas Campalagian Kabupaten Polewali Mandar yaitu Laliko dan yang paling terendah yaitu Padang.

\section{METODE}

Penelitian ini dilaksanakan di wilayah kerja Puskesmas Campalagian Kecamatan Campalagian Kabupaten Polewali Mandar pada bulan Mei-Juni 2019. Jenis penelitian yang digunakan adalah analitik observasional dengan desain penelitian case control. Populasi dalam penelitian ini adalah adalah seluruh balita usia 12 sampai 59 bulan yang berada di wilayah kerja Puskesmas Campalagian Kec. Campalagian Kabupaten Polewali Mandar dengan jumlah keseluruhan balita usia 12 sampai 59 bulan 626 dari 784 balita. Sampel diambil dengan tekhnik penentuan sampel menggunakan teknik proporsional random sampling.

Variabel terikat dalam penelitian ini adalah status balita gizi stunting, sedangkan variabel bebas terdiri dari Berat Badan Lahir Rendah (BBLR), pemberian ASI Eksklusif, pemberian MP-ASI. Data yang dikumpulkan antara lain data identitas subjek, berat badan lahir, tinggi badan, usia/umur, dan berat badan, pemberian ASI Eksklusif 0-6 bulan yang dikategorikan diberikan ASI Ekslusif dan tidak diberikan ASI Ekslusif, pemberian MPASI yang dikategorikan 6-24 bulan yang dikategorikan diberikan MP-ASI dan tidak diberikan MP-ASI.

Instrumen yang digunakan adalah kuesioner. Analisis data dengan program SPSS
21. Analisis univariat untuk mendeskripsikan setiap variabel penelitian. Analisis bivariat untuk melihat hubungan variabel dan besar risiko (OR) antara berat badan lahir, tinggi badan, usia/umur, dan berat badan, pemberian ASI Eksklusif, pemberian Mp-ASI yang dikategorikan dengan kejadian stunting pada anak usia 12 sampai 59 bulan. Analisis bivariat menggunakan uji Chi-Square dengan $\alpha$ 0,05 dan uji Fisher Exact.

\section{HASIL DAN PEMBAHASAN \\ Hasil Penelitian \\ Kriteria Responden}

Tabel : 1

\begin{tabular}{|c|c|c|}
\hline \multicolumn{3}{|c|}{$\begin{array}{c}\text { Kriteria Responden Berdasarkan } \\
\text { Berat Badan }\end{array}$} \\
\hline Berat Badan/Kg & $F$ & $\%$ \\
\hline $6-9 \mathrm{~kg}$ & 22 & 25,6 \\
\hline $10-13 \mathrm{~kg}$ & 56 & 65,1 \\
\hline $14-17 \mathrm{~kg}$ & 8 & 9,3 \\
\hline Total & 86 & 100,0 \\
\hline \multicolumn{3}{|c|}{$\begin{array}{c}\text { Kriteria Responden Berdasarkan } \\
\text { Tinggi Badan }\end{array}$} \\
\hline Tinggi Badan/cm & $F$ & $\%$ \\
\hline $69-77 \mathrm{~cm}$ & 8 & 9,3 \\
\hline $78-86 \mathrm{~cm}$ & 24 & 27,9 \\
\hline $87-95 \mathrm{~cm}$ & 28 & 32,6 \\
\hline $96-104 \mathrm{~cm}$ & 19 & 22,1 \\
\hline $105-113 \mathrm{~cm}$ & 7 & 8,1 \\
\hline Total & 86 & 100,0 \\
\hline
\end{tabular}

Karakteristik responden berdasarkan berat badan menunjukkan bahwa dari 86 responden maka berat badan dengan distribusi terbanyak ada pada berat badan $10-13 \mathrm{~kg}$ sebanyak 56 responden $(65,1 \%)$, dan untuk berat badan 6-9 $\mathrm{kg}$ sebanyak 22 responden $(25,6 \%)$. Sedangkan berat badan $14-17 \mathrm{~kg}$ sebanyak 8 responden $(9,3 \%)$.

Karakteristik responden berdasarkan tinggi badan menunjukkan bahwa dari 86 responden tinggi badan yang paling banyak adalah $87-95 \mathrm{~cm}$ sebanyak 28 responden $(32,6 \%)$, dan yang paling sedikit adalah $105-$ $113 \mathrm{~cm}$ sebanyak 7 responden $(8,1 \%)$, sedangkan $69-77 \mathrm{~cm}$ sebanyak 8 responden (9,3\%), 78-86 cm sebanyak 24 responden 
(27,9\%), 96-104 cm sebanyak 19 responden $(22,1 \%)$.

\section{Analisa Univariat}

Tabel : 2

\begin{tabular}{ccc}
\hline \multicolumn{4}{|c}{$\begin{array}{c}\text { Distribusi Frekuensi Responden } \\
\text { Berdasarkan Status Gizi }\end{array}$} \\
\hline Status gizi & $\boldsymbol{F}$ & $\mathbf{\%}$ \\
Tidak Stunting & 67 & 77,9 \\
\hline Stunting & 19 & 22,1 \\
\hline Total & $\mathbf{8 6}$ & $\mathbf{1 0 0 , 0}$ \\
\hline Distribusi Frekuensi Responden \\
Berdasarkan Riwayat INC \\
\hline Riwayat INC & $\boldsymbol{F}$ & $\mathbf{\%}$ \\
\hline BBLR & 7 & 8,1 \\
\hline BBLN & 79 & 91,9 \\
\hline Total & $\mathbf{8 6}$ & $\mathbf{1 0 0 , 0}$ \\
\hline Distribusi Frekuensi Responden \\
Berdasarkan & ASI Ekslusif \\
\hline ASI Ekslusif & $\boldsymbol{F}$ & $\mathbf{\%}$ \\
\hline Diberikan & 77 & 89,5 \\
\hline Tidak Diberikan & 9 & 10,5 \\
\hline Total & $\mathbf{8 6}$ & $\mathbf{1 0 0 , 0}$ \\
\hline Distribusi Frekuensi Responden \\
Berdasarkan MP-ASI \\
\hline Mp-ASI & $\boldsymbol{F}$ & $\mathbf{\%}$ \\
\hline Diberikan & 83 & 96,5 \\
\hline Tidak Diberikan & 3 & 3,5 \\
\hline Total & $\mathbf{8 6}$ & $\mathbf{1 0 0 , 0}$ \\
\hline Sumber : Data Primer, 2019 \\
Distribusi & frekuensi \\
\hline \multicolumn{3}{c}{ responden } \\
berdasarkan status gizi didapatkan bahwa & dari
\end{tabular}

86 responden sebagian besar balita tidak mengalami stunting sebanyak 67 responden

$(77,9 \%)$ dan yang mengalami stunting 19 responden $(22,1 \%)$.

Distribusi frekuensi responden berdasrkan riwayat INC didapatkan bahwa dari 86 responden riwayat INC paling banyak terjadi pada BBLN (berat badan lahir normal) sebanyak 79 responden $(91,9 \%)$ dan BBLR (berat badan lahir rendah) sebanyak 7 responden $(8,1 \%)$.

Distribusi frekuensi responden berdasarkan ASI Ekslusif didapatkan bahwa dari 86 responden ASI Ekslusif menunjukkan bahwa pada anak balita mayoritas diberikan ASI Ekslusif sebanyak 77 responden $(89,5 \%)$ dan yang tidak diberikan 9 responden $(10,5 \%)$.

Distribusi frekuensi responden berdasarkan MP-ASI didapatkan bahwa dari 86 responden MP-ASI menunjukkan bahwa pada anak balita mayoritas diberikan MP-ASI sebanyak 83 responden $(96,5 \%)$ dan yang tidak diberikan sebanyak 3 responden $(3,5 \%)$.

\section{Analisa Bivariat}

Analisa Bivariat dilakukan untuk mengartahui faktor yang mempengaruhi kejadian stunting pada balita usia 12 sampai 59 bulan. Uji statistik yang dilakukan adalah uji Chi Square, dengan komputerisasi pada tingkat kepercayaan menggunakan p-value <0,005 pada interval kepercayaan 95.

Tabel :3

Pengaruh Faktor Riwayat INC, ASI Ekslusif, MP-ASI Pada Kejadian Stunting Balita Usia 12-59 Bulan.

\begin{tabular}{|c|c|c|c|c|c|c|c|}
\hline & \multicolumn{6}{|c|}{ Status Gizi } \\
\hline & & $\begin{array}{c}\text { Tidak } \\
\text { Stunting }\end{array}$ & $\%$ & Stunting & $\%$ & Total & $\begin{array}{c}\mathbf{P} \\
\text { Value }\end{array}$ \\
\hline \multirow[t]{3}{*}{$\begin{array}{l}\text { Riwayat } \\
\text { INC }\end{array}$} & $\begin{array}{l}\text { BBLR 1500gr- } \\
2500 \mathrm{gr}\end{array}$ & 2 & 28,6 & 5 & 71,4 & 7 & 0,005 \\
\hline & $\begin{array}{c}\text { BBLN } \\
>2500 \mathrm{gr}-4000 \mathrm{gr}\end{array}$ & 65 & 82,3 & 14 & 17,7 & 79 & \\
\hline & Total & 86 & 110,9 & 19 & 89,1 & 86 & \\
\hline \multirow{2}{*}{$\begin{array}{l}\text { ASI } \\
\text { Ekslusif }\end{array}$} & Diberikan & 15 & 19,5 & 62 & 80,5 & 77 & 0,104 \\
\hline & Tidak diberikan & 4 & 44,4 & 5 & 55,6 & 9 & \\
\hline
\end{tabular}




\begin{tabular}{llcccccc}
\hline & Total & 19 & 63,9 & 67 & 136,1 & 86 & \\
\hline \multirow{2}{*}{ Mp-ASI } & Diberikan & 17 & 20,5 & 66 & 79,5 & 83 & 0,121 \\
& Tidak diberikan & 2 & 66,7 & 1 & 33,3 & 3 & \\
\hline & Total & 19 & 87,2 & 67 & 112,5 & 86 & \\
\hline
\end{tabular}

Sumber : Data Primer, 2019

Faktor riwayat INC didapatkan bahwa dari 7 responden yang mengalami BBLR, persentase tertinggi adalah kategori status gizi stunting yaitu sebanyak 5 responden $(71,4 \%)$, jika dibandingkan dengan kategori tidak stunting yaitu sebanyak 2 responden $(28,6 \%)$. Sedangkan dari 79 responden yang BBLN persentase tertinggi adalah kategori tidak stunting yaitu sebanyak 65 responden $(82,3 \%)$, jika dibandingkan dengan kategori stunting sebanyak 14 responden $(17,7 \%)$.

Untuk mengetahui pengaruh faktor riwayat INC (Berat Badan Lahir Rendah/BBLR) responden dengan kejadian stunting, maka dilakukan uji chi-square. Hasil analisa data dengan menggunakan uji chi-square maka di peroleh hasil $\mathrm{p}=0,005<\alpha$ 0,005 maka ini berarti $\mathrm{H} 1$ di terima dan $\mathrm{H} 0$ ditolak, maka ada pengaruh antara BBLR (Berat Bdan Lahir Rendah) terhadap kejadian Stunting di wilayah kerja puskesmas Campalagian di Kecamatan Campalagian.

Faktor pemberian ASI Ekslusif didapatkan bahwa dari 77 responden yang diberikan ASI Ekslusif, persentase tertinggi adalah kategori status gizi tidak stunting yaitu sebanyak 62 responden $(80,5 \%)$, jika dibandingkan dengan kategori stunting yaitu sebanyak 15 responden $(19,5 \%)$. Sedangkan dari 9 responden yang tidak diberikan persentase tertinggi adalah kategori tidak stunting yaitu sebanyak 5 responden $(55,6 \%)$, jika dibandingkan dengan kategori stunting sebanyak 4 responden $(44,4 \%)$.

Untuk mengetahui pengaruh faktor ASI Ekslusif responden dengan kejadian stunting, maka dilakukan uji chi-square. Hasil analisa data dengan menggunakan uji chi-square maka di peroleh hasil $\mathrm{p}=0,104$ $\alpha>0,05$ maka ini berarti $\mathrm{H} 1$ di tolak dan $\mathrm{H} 0$ diterima, maka tidak ada pengaruh antara ASI Ekslusiif terhadap kejadian Stunting di wilayah kerja puskesmas Campalagian di Kecamatan Campalagian.

Faktor pemberian MP-ASI didapatkan bahwa dari 83 responden yang diberikan Mp-ASI, persentase tertinggi adalah kategori status gizi tidak stunting yaitu sebanyak 66 responden $(79,5 \%)$, jika dibandingkan dengan kategori stunting yaitu sebanyak 17 responden $(20,5 \%)$. Sedangkan dari 3 responden yang tidak diberikan persentase tertinggi adalah kategori stunting yaitu sebanyak 2 responden $(66,7 \%)$, jika dibandingkan dengan kategori tidak stunting sebanyak 1 responden $(33,3 \%)$.

Untuk mengetahui pengaruh faktor Mp-ASI responden dengan kejadian stunting, maka dilakukan uji chi-square. Hasil analisa data dengan menggunakan uji chi-square maka di peroleh hasil $\mathrm{p}=0,121<\alpha$ 0,005 maka ini berarti $\mathrm{H} 1$ di tolak dan $\mathrm{HO}$ diterima, maka tidak ada pengaruh antara Mp-ASI terhadap kejadian stunting di wilayah kerja puskesmas Campalagian di Kecamatan Campalagian.

\section{PEMBAHASAN}

Berdasarkan hasil analisis data dan disesuaikan dengan tujuan penelitian serta kerangka konsep penelitian, maka pembahasan di kemukakan sebagai berikut :

\section{BBLR (Berat Badan Lahir Rendah)}

BBLR adalah BB bayi <2500 gr yang terbagi atas 2 macam yaitu bayi $\mathrm{KB}$ (umur kehamilan 37 minggu) dan KMK atau bayi kecil masa kehamilan (bayi dilahirkan kurang dari percentil ke-10 kurva pertumbuhan janin (Sukarni \& Sudarti, 2014).

Pada tabel 2 didapatkan bahwa dari 7 responden yang mengalami BBLR, 
persentase tertinggi adalah kategori status gizi stunting yaitu sebanyak 5 responden $(71,4 \%)$, jika dibandingkan dengan kategori tidak stunting yaitu sebanyak 2 responden $(28,6 \%)$. Sedangkan dari 79 responden yang normal persentase tertinggi adalah kategori tidak stunting yaitu sebanyak 65 responden $(82,3 \%)$, jika dibandingkan dengan kategori stunting sebanyak 14 responden $(17,7 \%)$.

Hal ini menunjukkan bahwa semakin banyak balita yang mempunyai riwayat BBLR yang dialami responden maka semakin tinggi pula kejadian stunting. Secara statistik didapatkan $\mathrm{P}=0,005$ $(p<0,05)$ H1 di terima dan Ho di tolak, hal ini menunjukkana adanya pengaruh antara BBLR (berat badan lahir rendah) dengan kejadian stunting.

Hal ini didukung hasil penelitian yang dilakukan (Rahayu, Yulidasari, Putri, \& Rahman, 2015), yang mennyimpulkan bahwa riwayat berat badan lahir rendah (BBLR) merupakan salah satu faktor yang potensial mempengaruhi pertumbuhan pada anak. (Fitri, 2018), yang menyimpulkan bahwa berat badan lahir rendah memiliki hubungan dengan kejadian stunting dimana bayi yang BBLR beresiko 1.665 kali mengalami stunting dibandingkan dengan bayi yang lahir normal. (Hanum, 2019) yang menyimpulkan bahwa berat badan lahir rendah sangat berisko terhadap stunting.

Menurut Kristyanasari, 2010 Status gizi ibu pada waktu pembuahan dan selama hamil dapat mempengaruhi pertumbuhan janin yang sedang dikandung.

Menurut Prawirohardjo, 2008 penyakit pada saat kehamilan yang dapat mempengaruhi berat bayi lahir diantaranya adalah Diabetes Melitus Gestasional (DMG), cacar air, dan penyakit infeksi TORCH. Penyakit DMG adalah intoleransi glukosa yang dimulai atau baru ditemukan pada waktu hamil. Tidak dapat dikesampingkan kemungkinan adanya intoleransi glukosa yang tidak diketahui yang muncul seiring kehamilan, komplikasi yang mungkin sering terjadi pada kehamilan dengan diabetes adalah bervariasi. Pada ibu akan meningkatkan risiko terjadinya preeklamsia, secsio sesaria, dan terjadinya diabetes mellitus tipe 2 di kemudian hari, sedangkan pada janin meningkatkan risiko terjadinya makrosomi. Penyakit infeksi TORCH adalah suatu istilah jenis penyakit infeksi yaitu Toxoplasma, Rubella, Cytomegalovirus dan Herpes.

Berdasarkan hasil penelitian diketahui bahwa pada umumnya responden memiliki berat badan yang tidak sesuai dengan tinggi badan maupun umur balita.

Menurut pengamatan peneliti, faktor yang mempengaruhi BBLR salah satu diantaranya yaitu jarak kehamilan sangat mempengaruhi kesehatan ibu dan janin yang dikandungnya. Seorang wanita memerlukan waktu selama 2 - 3 tahun agar dapat pulih secara fisiologis dari satu kehamilan atau persalinan dan mempersiapkan diri untuk kehamilan yang terlalu dekat memberikan indikasi kurang siapnya rahim untuk terjadi implantasi bagi embrio.

\section{ASI Ekslusif}

Air Susu Ibu Eksklusif yang selanjutnya disebut ASI Eksklusif adalah ASI yang diberikan kepada bayi sejak dilahirkan selama 6 (enam) bulan, tanpa menambahkan dan/atau mengganti dengan makanan atau minuman lain (Presiden RI, 2012), (Akbar et al., 2018).

Pada Tabel 2 didapatkan bahwa dari 77 responden yang diberikan Asi Ekslusif, persentase tertinggi adalah kategori status gizi tidak stunting yaitu sebanyak 62 responden $(80,5 \%)$, jika dibandingkan dengan kategori stunting yaitu sebanyak 15 responden $(19,5 \%)$. Sedangkan dari 9 responden yang tidak diberikan persentase tertinggi adalah kategori tidak stunting yaitu sebanyak 5 responden $(55,6 \%)$, jika dibandingkan dengan kategori stunting sebanyak 4 responden $(17,7 \%)$.

Hal ini menunjukkan bahwa semakin tinggi pemberian Asi Ekslusif pada 
responden maka semakin kurang pula angka kejadian stunting yang terjadi pada balita. Secara statistik didapatkan $\mathrm{P}=0,104$ (p>0,005) H1 di tolak dan Ho di terima, hal ini menunjukkan tidak adanya pengaruh antara ASI Ekslusif dengan kejadian stunting.

Hal ini didukung hasil penelitian yang dilakukan (Paramashanti, Ata, Hadi, Ata, \& Gunawan, 2016) , yang mennyimpulkan bahwa ASI eksklusif bukanlah satu-satunya faktor yang berkontribusi terhadap kejadian stunting pada anak. Pemberian gizi yang optimal juga harus diperhatikan. Perbaikan status gizi sejak masa prekonsepsi dan selama kehamilan, serta status ekonomi rumah tangga diharapkan mampu menurunkan kejadian stunting pada anak. (Meilyasari \& Isnawati, 2014), yang menyimpulkan bahwa lama pemberian ASI Eksklusif bukan merupakan faktor risiko stunting dikarenakan sebagian ibu mengkombinasikan ASI dengan susu formula sehingga kebutuhan zat gizi balita tetap terpenuhi dan tidak mengganggu pertumbuhan. (Vaozia \& Nuryanto, 2016), riwayat ASI Eksklusif merupakan riwayat pemberian Air Susu Ibu (ASI) sejak setelah persalinan, diberikan tanpa diberi makanan lain selain ASI sampai bayi usia 6 bulan bukan merupakan faktor risiko terjadinya stunting.

Menurut Yuliandarin, 2009, ibu yang diberikan dukungan oleh suami memiliki peluang 12,98 kali lebih besar untuk menyusui secara eksklusif dibandingkan ibu yang tidak mendapat dukungan.

Menurut Akbar et al., 2018, Budaya turut mempengaruhi pemberian ASI Eksklusif karena pada masyarakat di Indonesia sangat menghargai tradisi yang telah ada sebelumnya.

Menurut Novita, 2008, Ibu yang berumur di bawah 30 tahun lebih banyak yang memberikan ASI secara eksklusif daripada ibu yang berusia diatas 30 tahun. Terjadi pembesaran payudara setiap siklus ovulasi dari awal terjadi menstruasi sampai usia 30 tahun, namun terjadi degenerasi payudara dan kelenjar penghasil ASI secara keseluruhan setelah usia 30 tahun.

Berdasarkan hasil penelitian diketahui bahwa pada umumnya responden rata-rata diberikan Asi Ekslusif yang dapat menunjang pertumbuhan balita.

Menurut pengamatan peneliti, pemberian ASI ekslusif sangat menunjang bagi pertumbuhan balita tapi sebaliknya bisa saja ASI ekslusif sangat berpengaruh terhadap kejadian stunting dipengaruhi oleh berbagai faktor, salah satu diantaranya ASI eksklusif bukanlah satu-satunya faktor yang berkontribusi terhadap kejadian stunting pada anak yaitu pekerjaan Ibu yang tidak bekerja/berada di rumah memiliki kemungkinan besar untuk memberikan ASI secara Eksklusif

\section{MP-ASI}

MP-ASI diberikan tepat pada usia 6-24 bulan karena pada usia tersebut merupakan waktu yang sangat rawan terjadi malnutrisi dan pencernaan bayi mulai kuat. Mp-ASI yang diberi terlalu dini akan menurunkan konsumsi ASI dan bayi mengalami gangguan pencernaan atau dapat terkena diare. Sebaliknya, bila Mp- ASI terlambat diberikan akan mengakibatkan anak kurang gizi bila terjadi dalam waktu panjang (Khomsan, 2008), (Akbar et al., 2018).

Pada Tabel 2 didapatkan bahwa dari 83 responden yang diberikan MP-Asi, persentase tertinggi adalah kategori status gizi tidak stunting yaitu sebanyak 66 responden $(79,5 \%)$, jika dibandingkan dengan kategori stunting yaitu sebanyak 17 responden (20,5\%). Sedangkan dari 3 responden yang tidak diberikan persentase tertinggi adalah kategori stunting yaitu sebanyak 2 responden (66,7\%), jika dibandingkan dengan kategori tidak stunting sebanyak 1 responden $(33,3 \%)$.

Hal ini menunjukkan bahwa semakin tinggi pemberian Mp-ASI pada responden terhadap kejadian stunting maka semakin kurang pula angka kejadian stunting yang terjadi pada balita. Secara 
statistik didapatkan $\mathrm{P}=0,121(\mathrm{p}>0,05) \mathrm{H} 1 \mathrm{di}$ tolak dan Ho di terima, hal ini menunjukkan tidak adanya pengaruh antara Mp-ASI dengan kejadian stunting.

Hal ini didukung hasil penelitian yang dilakukan (Paramashanti et al., 2016), yang mennyimpulkan bahwa ASI eksklusif bukanlah satu-satunya faktor yang berkontribusi terhadap kejadian stunting pada anak. Pemberian Mp-ASI yang optimal juga harus diperhatikan. Perbaikan status gizi sejak masa prekonsepsi dan selama kehamilan, serta status ekonomi rumah tangga diharapkan mampu menurunkan kejadian stunting pada anak. (Meilyasari \& Isnawati, 2014), yang menyimpulkan bahwa pemberian Mp-ASI sangat menunjang terhadap pertumbuhan dan perkembangan anak pada masa balita. (Hanum, 2019), yang menyimpulkan bahwa balita yang diberikan Mp-ASI dengan tepat sesuai usia berpeluang 1,568 kali tumbuh tidak stunting dari pada balita yang diberikan Mp-ASI tidak tepat.

Menurut Khomsan, 2008, Mp-ASI diberikan tepat pada usia 6-24 bulan karena pada usia tersebut merupakan waktu yang sangat rawan malnutrisi dan pencernaan bayi mulai kuat. Mp-ASI yang diberi terlalu dini akan menurunkan konsumsi ASI dan bayi mengalami gangguan pencernaan atau dapat terkena diare. Sebaliknya, bila Mp-ASI terlambat diberikan akan mengakibatkan anak kurang gizi bila terjadi dalam waktu panjang.

Menurut IDAI dan WHO, ASI hanya memenuhi kebutuhan bayi sekitar 70 persenpada rentang usia 6-8 bulan, 50 persen pada rentang usia 9-11 bulan dan hanya 30 persesn diatas satu tahun. Artinya Mp-ASI sangat penting diberikan sejak bayi berusia 6 bulan untuk dapat melengkapi kebutuhan energinya.

Dalam pemberian Mp-ASI bergizi seimbang menurut WHO/UNICEF mudah sekali, bayi boleh makan apa saja dari menu meja makan keluarga dan harus diperhatikan : frequency (frekuensi MpASI), amount (jumlah takaran Mp-ASI), thicness (tekstur makanan Mp-ASI), variety (jenis), active/responsive feeding dan higiene.

Berdasarkan hasil penelitian diketahui bahwa pada umumnya responden rata-rata diberikan Mp-ASI yang dapat menunjang pertumbuhan balita.

Menurut pengamatan peneliti, pemberian Mp-ASI sangat menunjang bagi pertumbuhan balita tapi sebaliknya bisa saja Mp-ASI sangat berpengaruh terhadap kejadian stunting.

\section{KESIMPULAN DAN SARAN Kesimpulan}

Dari hasil penelitian bahwa BBLR berpengaruh terhadap kejadian stunting pada balita usia 12 sampai 59 bulan di wilayah kerja Puskesmas Campalagian dengan $\mathrm{p}=0,004<\alpha 0,005$, sedangkan ASI Ekslusif dengan $\mathrm{p}=0,104>\alpha 0,05$ dan MpASI dengan $\mathrm{p}=0,121>\alpha \quad 0,005$, tidak berpengarruh terhadap kejadian stunting ada balita usia 12 sampai 59 bulan di wilayah kerja Puskesmas Campalagian.

\section{Saran}

Bagi Profesi Perawat

Hasil penelitian ini merupakan suatu masukan bagi profesi perawat untuk menjadi salah satu acuan dan referensi ilmiah untuk dikembangkan lebih lanjut dan menjadi bahan untuk menambah pengetahuan dan wawasan mengenai faktor yang mempengaruhi masalah gizi pada balita.

Bagi STIKES Bina Generasi

Hasil penelitian ini merupakan suatu masukan bagi STIKes Bina Generasi untuk menjadi referensi bagi mahasiswa keperawatan, kebidanan, dan pengajar sebagai bahan masukan untuk penelitian selanjutnya serta dapat membantu balita dalam meningkatkan status gizi.

Bagi Puskesmas Campalagian

Hasil penelitian ini merupakan suatu masukan bagi pihak puskesmas setempat untuk lebih meningkatkan kinerjanya dalam menangani masalah gizi pada ibu hamil untuk meningkatkan derajat kesehatan pada anak yang lahir.

Bagi Dinas Kesehatan 
Hasil penelitian ini diharapkan menjadi bahan masukan dan informasi bagi Dinas Kesehatan untuk lebih meningkatkan pelayanan sarana kesehatn dengan melakukan penyuluhan-peyuluhan yang dapat mendukung dalam hal meningkatkan derajat kesehatan gizi ibu hamil.

Bagi Penulis

Merupakan pengalaman yang sangat berharga dalam rangka menambah wawasan dan ilmu pengetahuan untuk mengetahui faktor yang mempengaruhi kejadian stunting pada balita.

Bagi Masyarakat

Hasil penelitian ini diharapkan menjadi bahan pertimbangan dan masukan bagi keluarga dan masyarakat akan pentingnya pemeliharaan kesehatan melalui upaya pemanfaatan sarana kesehatan (Puskesmas) yang berada ditempat tinggalnya agar dapat memanfaatkan dengan sebaik-baiknya dengan rutin melakukan pemeriksaan kepuskesmas atau fasilitas kesehatan yang berada diwilayah sekitar tempat tinggalnya

Bagi Pembaca

Hasil penelitian ini dapat dijadikan sebagai bahan acuan bagi keluarga yang memiliki anak untuk meningkatkan status keksehatan gizi anak yang memiliki anak dengan status gizi kurang.

\section{DAFTAR PUSTAKA}

Akbar, A. A., Syamsianah, A., \& Setiawati, Y. N. (2018). Berat badan Lahir Rendah, Lama Pemberian ASI dan ASI Ekslusif Sebagai Faktor Risiko kejadian Stunting Balita di Desa Langesari Kabupaten Semarang.

Angkat, A. H. (2018). Penyakit Infeksi dan Praktek Pemberian MP-ASI Terhadap Kejadian Stunting Pada Anak Usia 12-36 Bulan di Kecamatan Simpang Kiri Kota. Journal of The World of Nutrition, $1(1)$, 52-58. https://doi.org/https://ejournal.helve tia.ac.id/jdg

Apriani, L. (2018). Hubungan Karakteristik Ibu, Pelaksanaan Keluarga Sadar Gizi (KADARZI) dan Perilaku
Hidup Bersih Sehat (PHBS) dengan Kejadian Stunting. JURNAL KESEHATAN MASYARAKAT (e-Journal), 6(4), 198-205. https://doi.org/http://ejournal3.undi p.ac.id/index.php/jkm oleh

Fitri, L. (2018). Hubungan BBLR dan ASI Ekslusif dengan Kejadian Stunting di Puskesmas Lima Puluh Pekanbaru. Jurnal Edurance, 3(1), 131-137.

https://doi.org/http://doi.org/10.222 16/jen.v3i1.1767 ABSTRAK

Hanum, N. H. (2019). Hubungan Tinggi Badan Ibu dan Riwayat Pemberian MP-ASI dengan Kejadian Stunting pada Balita Usia 24-59 Bulan. Amerta Nutrition, 78-84. https://doi.org/10.2473/amnt.v3i2.2 019.78-84

Kullu, V. M., Yasnani, \& Hariati, L. (2018). Faktor-faktor yang Berhubungan dengan Kejadian Stunting Pada Balita Usia 24-59 Bulan di Desa Wawatu Kecamatan Moramo Utara Kabupaten Konawe Selatan Tahun 2017. Jurnal Ilmiah Mahasiswa Kesehatan Masyarakat, 3(2), $\quad 1-11$. https://doi.org/http:garuda.ristekdik ti.go.id

Lapau, B. (2012). Metode penelitian Kesehatan: Metode Ilmiah Penulisan Skripsi, Tesis dan Disertasi (Edisi 1). Jakarta: Yayasan Pustaka Obor Indonesia.

Meilyasari, F., \& Isnawati, M. (2014). Faktor Risiko Kejadian Stunting pada Balita Usia 12 bulan di Desa Purwokerto Kecamatan Patebon, Kabupaten Kendal. Journal of Nutrition College, 3(2), 26-32. https://doi.org/http://ejournals1.undip.ac.id/index.php/jnc

Musdalifah. (2015). Hubungan Pengetahuan Ibu Tentang Stimulasi dengan Perkembangan Motorik Kasar dan Halus Pada Balita Usia 3-5 Tahun di Desa Karama Kec. Tinambung. 
Nadiyah, Briawan, D., \& Martianto, D. (2014). Faktor Risiko Stunting Pada Anak Usia 0-23 Bulan di Provinsi Bali, Jawa Barat, dan Nusa Tenggara Timur. Jurnal Gizi Dan Pangan, 9(2), 125-132.

Notoadmodjo, S. (2010). Metodelogi Penelitian Kesehatan. Jakarta: Rineka.

Nursalam. (2008). Konsep dan Penerapan Metodelogi Penelitian Ilmu Keperawatan. Jakarta: Salemba Medika.

Paramashanti, B. A., Ata, U. A., Hadi, H., Ata, U. A., \& Gunawan, I. G. (2016). Pemberian ASI eksklusif tidak berhubungan dengan stunting pada anak usia $6-23$ bulan di Indonesia. Jurnal Gizi Dan Diedetik Indonesia, 3(August 2018). https://doi.org/10.21927/ijnd.2015. 3(3). $162-174$

Pormes, W. E., Rompas, S., \& Ismanto, A. Y. (2015). Hubungan Pengetahuan Orang Tua Tentang GiziI dengan Stunting Pada Anak Usia 4-5 Tahundi TK Malaekat Pelindung Manado.

Rahayu, A., Yulidasari, F., Putri, A. O., \& Rahman, F. (2015). Riwayat Berat Badan Lahir dengan Kejadian Stunting pada Anak Usia Bawah Dua Tahun. Jurnal Kesehatan Masyarakat Nasional, 10, 67-73. https://doi.org/http://dx.doi.org/10.2 1109/kesmas.v10i2.882
RI, K. K. (2018). Buletin Jendela Data dan Informasi Kesehatan. Jakarta.

Riskesda. (2013). Riset Kesehatan Dasar. Jakarta.

Romarina, A. (2016). Capaian Pelayanan Kesehatan Dasar Di Kota Pekanbaru. Jurnal Ilmu Sosial, 16(1), 47-57. https://doi.org/http://ejournal.undip. ac.id

Sukarni, I., \& Sudarti. (2014). Patologi: Kehamilan, Persalinan, Nifas dan Neonatus Risiko Tinggi (Edisi 1). Yogyakarta.

Sumantri, A. (2015). Metodelogi Penelitian Kesehatan. In Europe (Edidi Pert, pp. 224-226). Jakarta: Kencana Prenada Media Grup.

Swarjana, I. K. (2012). Metode Penelitian Kesehatan Tuntunan Praktis Pembuatan Proposal Kesehatan (Edisi 1). Yogyakarta: Andi Offset.

Swarjana, I. K. (2015). Metodologi Penelitian Kesehatan (Edisi $1 \mathrm{Re}$ ). Yogyakarta.

Vaozia, S., \& Nuryanto. (2016). Faktor Risiko Kejadian Stunting pada Anak Usia 1-3 Tahun (Studi di Desa Menduran Kecamatan Brati Kabupaten Grobogan). Journal of Nutrition College, 5(4), 314-320. https://doi.org/http://ejournals1.undip.ac.id/index.php/jnc

Welasasih, B., \& Wirjatmadi, R. (2012). Beberapa Faktor yang Berhubungan Dengan Status Gizi Balita Stunting. 